\title{
New self-sufficient shelter solutions for big cities' collapsed rental markets
}

\author{
A. Galiano, A. Fernández, J. Antón \& C. Ortiz \\ Department of Building Technology, University of Alicante, Spain
}

\begin{abstract}
Nowadays, there is a wide variety of problems in the big cities related to the urban frame and to housing. Architects have to provide solutions that not only improve people's well-being but also have to be efficient during the building's entire life cycle.

Within the European context, big cities like Paris, Berlin and Amsterdam have a huge demand for housing coming mainly from two different groups: people looking for temporary shelter and people looking for a more stable situation. In both cases, the need for new housing have resulted in inefficient urban developments, collapsed city centres and developed satellite cities where low and medium class people have tried to find somewhere to live, running away from infra-housing. In Paris, urban regulations set the minimum area for a rented apartment as $10 \mathrm{~m}^{2}$.

The research described in this paper analyzes the current situation in big cities from two points of view: apartment sizes and medium fees for temporary shelter. It defines the average architectural conditions of the "affordable" shelter and with this data; an experimental approach for a new completely self-sufficient housing module is provided, placed in a worthless space of existing buildings (roofs). This new module is defined by its sustainability and self-sufficiency and it gives the rental market an opportunity to increase the offer of shelter to rent in the big cities. At the end of the research, the development of an analysis of life cost cycle of the new module shows it as an alternative to the existing examples of infra housing with very short periods for recovering the investment.
\end{abstract}

Keywords: microhousing, residential solutions, self-suffiency, urban strategies development, urban density. 


\section{Analysis and situation of modern urban agglomerations}

The demand for housing in large cities can cause major problems for some segments of society. Alongside those seeking temporary accommodation are others in need of longer-term housing. Over time, migration to large urban agglomerations has prompted inefficient urban growth. Densification is seen as a positive strategy for tackling infrastructure problems, overcrowding in city centres and the creation of satellite towns where more underprivileged groups have found accommodation.

Space has always been at a premium in city centres, resulting in extremely high prices and a drastic reduction in the size of housing units with a view to obtaining maximum profit for constructed spaces. Units measuring $10 \mathrm{~m}^{2}$ have become real housing solutions, where unhealthy conditions and a lack of basic infrastructures (such as a bathroom) are compounded by exorbitant monthly rents (Maurer et al. [1]).

\subsection{Paris case study: an introduction}

The situation of large urban agglomerations differs according to their history. In addition, between countries, cultural factors generate differences in the situation of similarly sized cities, while within the same country, the housing stock, urban planning, the property market, user preferences and gentrification all give rise to completely different conflicts within rented accommodation supply and demand.

In spite of these differences, there are also several common concerns. These include the need to achieve sustainable urban planning in the medium and long term and balance housing supply and demand for new citizens and their housing needs, and the question of how to tailor original services and infrastructures to modern buildings and manage the daily movement of millions of people. All of the above has prompted the authorities to take measures aimed at redressing the balance.

Of all the urban clusters that display similar behaviours, this research focused on the case of Paris, which presents clear differences to other major cities in many regards but also many similarities (De Palma et al. [2]).

Paris is the largest urban agglomeration in France with a municipal area covering $105.4 \mathrm{~km}^{2}$. It is home to $2,249,975$ people, and a vast metropolitan area that sprawls over $14,518 \mathrm{~km}^{2}$ and has $12,292,895$ inhabitants. The largest cohort in its population pyramid comprises 25 to 27 year olds, for three key reasons. Firstly, Paris is where at least $50 \%$ of the country's major companies have their headquarters, and many professional posts in France are based in the district of La Defense. Secondly, Paris has 13 public universities and the country's largest faculties; thus many students reside temporarily in Paris or in one of its satellite towns when they are studying. Thirdly, Paris offers services and employment opportunities that simply do not exist elsewhere in the country (Perrel [3]). 


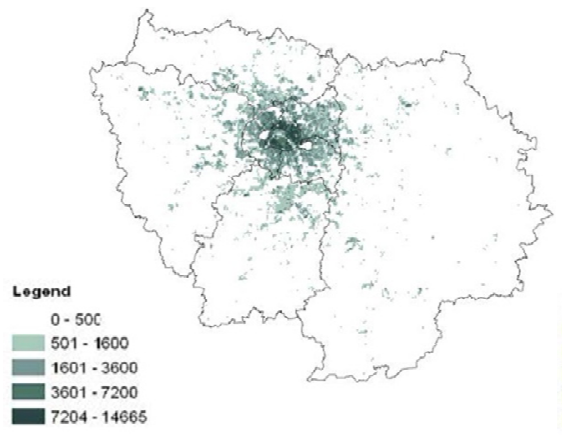

Figure 1: Population density.

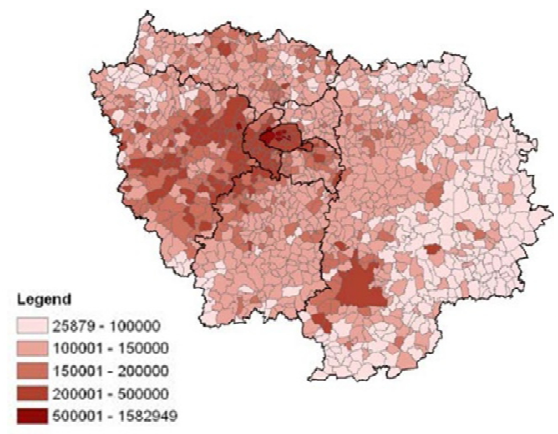

Figure 3: Price of $\mathrm{m}^{2}$ for flats.

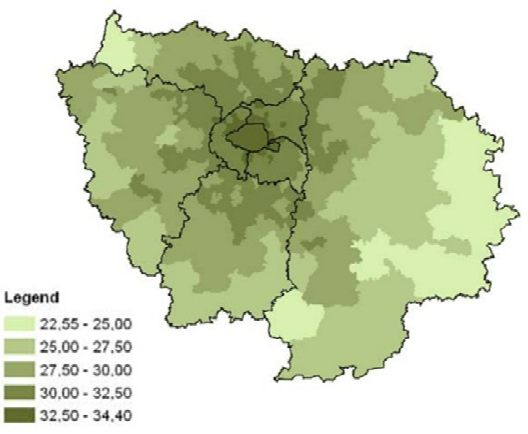

Figure 2: Environmental quality.

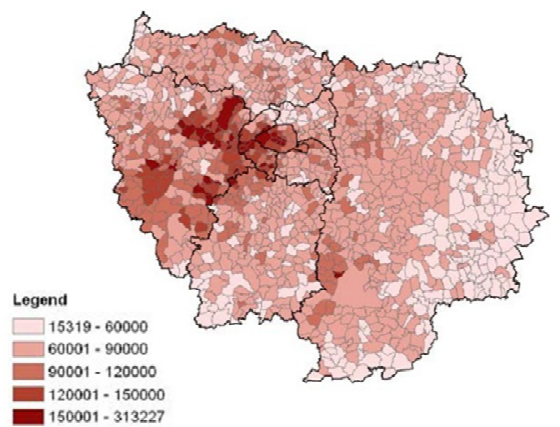

Figure 4: Price of $\mathrm{m}^{2}$ for houses.

(Source: De Palma et al. [2].)

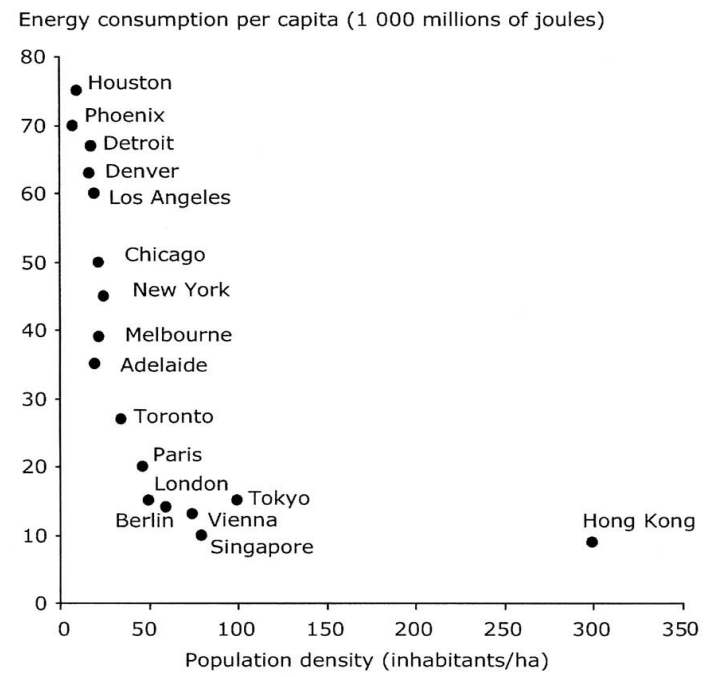

Figure 5: Consumption per capita and city density comparison. 


\subsection{Analysis of the condition of the housing stock in Paris}

The population pyramid in the city of Paris is reflected in the distribution of family units. Single-person homes account for $44 \%$ of units, childless couples for $21 \%$, couples with children for $29 \%$, and single-parent families for $6 \%$. An analysis of this information indicates that just $35 \%$ of Parisian family units have children.

The ratio of housing/family units is 1:01, whereas in the rest of France this figure increases to $1: 23$. An analysis of these figures indicates that the property market is demand-driven, which has pushed up the price of land per $\mathrm{m}^{2}$ to sometimes exorbitant levels that are nevertheless accepted owing to the lack of supply.

In 2013 , the average rent was $€ 20.8 / \mathrm{m}^{2}$ and the average purchase price was $€ 7,515 / \mathrm{m}^{2}$. Price ranges are conditioned by a whole host of factors, including the services available, location, density and demand for housing in the area. However, it has undoubtedly become a luxury market with astronomical prices even for properties that barely measure $10 \mathrm{~m}^{2}$.

A study of first homes conducted in 2013 showed that $61.3 \%$ were of good quality, $34.2 \%$ were of average quality and $4.5 \%$ could be considered to be of poor quality. An analysis of the traceability of these data reveals that this situation is a little different to the one observed in 2006. The municipality of Paris presented the greatest divergence, with $6.6 \%$ of poor quality housing in 2013 due to the age of the housing stock. In the petite couronne, the percentage of poor quality housing was within the regional average, $4.5 \%$, while in the grande couronne this percentage dropped to $3.1 \%$ since the buildings were generally newer.

The petite couronne represents the most significant case of overcrowding. According to the French National Institute for Statistics and Economic Studies (INSEE), $17.7 \%$ of homes are currently estimated to present an unsatisfactory ratio between the number of $\mathrm{m}^{2}$ or rooms and the number of inhabitants (Labrador et al. [4]).

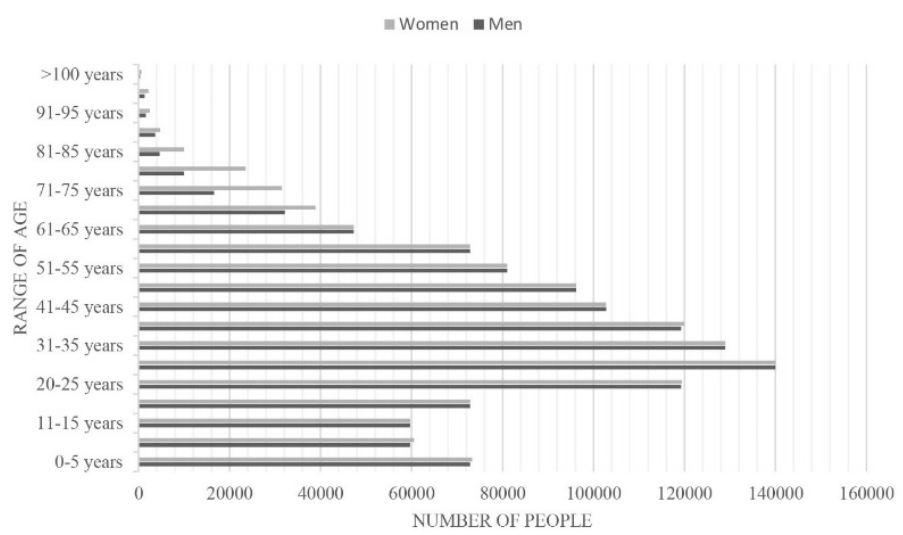

Figure 6: Paris population pyramid. 
Another of the problems generated by older housing is high-energy consumption. Some $25 \%$ of the deficiencies detected by the INSEE in its technical inspections are linked to inefficient heating systems or a lack of insulation.

Furthermore, in addition to deficiencies related to energy consumption, damp is a frequent problem, caused by a lack of adequate insulation and the failure to maintain external walls and roofs.

In spite of the state of conservation of the buildings, housing is extremely important to residents of Paris. According to the OECD, national statistics indicate that French citizens spend on average $21 \%$ of their gross earnings on rent or a mortgage. Bearing in mind that employees aged 25-30 years old earn on average $€ 1,538$ a month ( $€ 18,460$ a year), the average housing costs for the most prevalent age range in Paris is $€ 322.98$, equivalent to around $16 \mathrm{~m}^{2}$ according to the average price per $\mathrm{m}^{2}$ for rented properties (Perrel [3] and OCDE [5]).

\subsection{Improvement strategies in major cities}

The densification and proximity strategies implemented in the world's major cities are proving capable of generating increasingly efficient city models in many respects, including energy consumption. Density exerts three effects that are directly linked to energy consumption: it limits and reduces use of private cars, the distance travelled and the number of trips made. It also makes it possible for people to cover these distances on foot or by public transport.

Besides density, another factor that could help to reduce travel using private transportation, one of the main causes of energy consumption in cities is commuting distance and concentration. If a balance can be struck between these three factors, consumption in the city will be substantially reduced and quality of life increased.

The other main source of consumption in cities is heating and air conditioning in the home. The use of more energy-efficient appliances, together with various energy saving measures, could further reduce consumption in cities and would also create healthier environments within homes, buildings and public spaces.

There is no sole urban planning solution to all these problems. Short-term strategies could include expanding the city limits, renewing housing stock, renovating some of the housing stock, leveraging existing traditional housing, as APUR - Atelier Parisien d'Urbanisme [6] suggests, or developing unused spaces with modular architecture.

\section{Research description}

\subsection{Research rationale}

There is a need within this complex framework to explore all suitable technological alternatives and solutions available to improve the quality of life of the inhabitants of urban agglomerations. Starting from the premise that densification is a valid tool to improve city spaces, as Navarro Vera and Ortuño Padilla defend [7]; the aim of this research was to explore the colonisation of 
worthless space in existing buildings using expansive, minimal intervention techniques based on dry construction methods. The aim was to study the viability of new spaces located on the roofs of existing buildings that could be used as rental properties. Such spaces should offer quality accommodation and efficiency, and require a low level investment.

It is intended to demonstrate that the cost of these kinds of interventions is not high and it can be a motivation for the owners of these examples of infra housing in order to offer a worthy alternative to the temporary housing applicants.

Those districts with a high demand of housing for rent and with the lowest quality were the objective of this research. In the case of Paris, districts 13,14 and 15 , in the south part of the city present a worrying situation but it is the district number 13 where lowest quality housing with higher rental fess can be found. Therefore, an alternative for the existing rental offer is needed in this area in order to avoid abusive practices that affect many people in something so necessary like housing.

It was intended to develop a strategy where worthless spaces of buildings could be used to host new living areas. The choice of the roofs of existing buildings as a possible site for these extensions was based on the capacity of these spaces to house new constructions with lighting conditions that in some cases are better than those of properties located on lower floors. Traditionally, these spaces have been used to house domestic staff and installations, and thus a change of approach would improve these areas while at the same time generating attractive architectural spaces.

Using dry construction techniques, we aimed to study the viability of these new spaces, which could be used as rental properties, located on the roofs of existing buildings. This prefabricated module, which could be installed in various locations, should be capable of providing an alternative to traditional rental properties and be economically viable for the owners of the building. In terms of providing quality of life to its inhabitants, the module should offer almost complete energy self-sufficiency while also improving on the environmental conditions of similarly sized rental spaces.

\subsection{Case study: selection of the location and building}

As mentioned before, the higher rental demand occurs in the periphery of the city inside the petit couronne of Paris. In the above mentioned districts the average rent rises up to $€ 30 \mathrm{~m}^{2}$ and the average age of the buildings is 50 years but with low quality construction.

In order to be able to carry out this research it was needed to find buildings with the proper characteristics to host prefabricated modules in the roof; flat roof, structural stability, roof access and minimum installations. District $n^{\circ} 13$ had many examples of these types of buildings with different ages and levels of maintenance. 


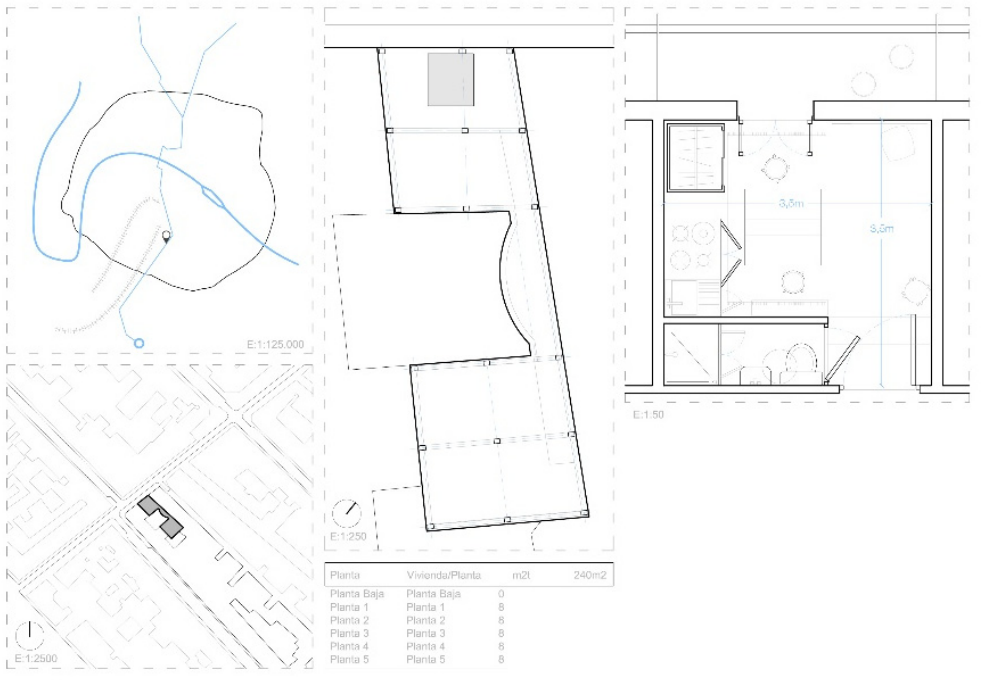

Figure 7: Selection of the location.

\subsection{The architectural concept}

The architectural concept was based on prefabrication and industrialization of the construction. It was intended to work with the concept of module with dimensions that allow an easy transportation and location. The concept of box that could be transported in a truck was seen as a real option because space flexibility could be explored, construction fully controlled and lightweight guaranteed.

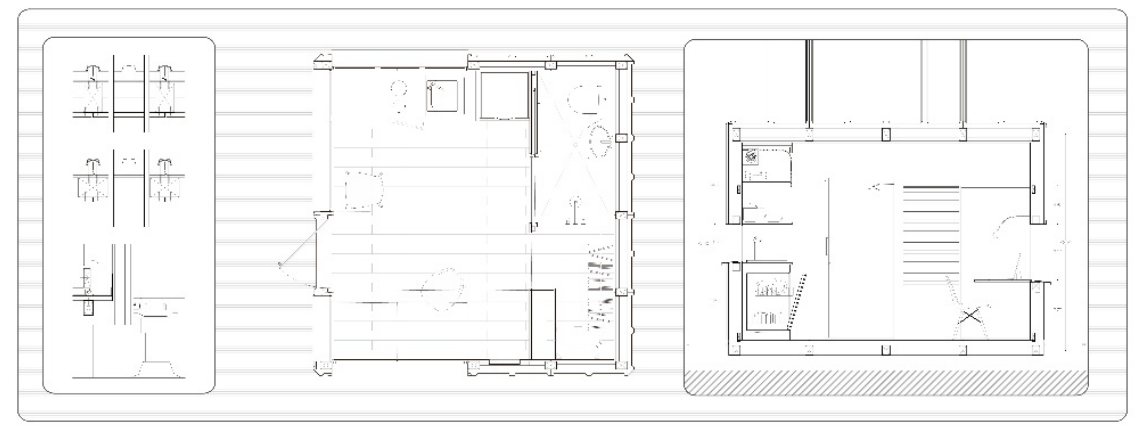

Figure 8: Module floor plan and section.

The module should act as a minimum individual housing example with all the facilities that a regular house must have but with a high degree of flexibility in order to reduce space. As one of the requirements was related to the energy inefficiency of the existing rental offer, one of the challenges was designing a 
sufficient energy solution that must reduce the impact of the new module at two scales, the scale of the building where it would be located and the scale of the city. Therefore efficient conditioning solutions and proper thermal isolations must be a very important part of the design and renewal systems must be integrated on it.

\subsection{Description of the module}

The module is designed for a single inhabitant with a floor space of $16 \mathrm{~m}^{2}$. Flexibility is paramount within such a space, and therefore only spaces where privacy is paramount were partitioned off from the rest. The possibility of using double spaces is also studied providing the space for sleeping in a semi-level above the living area.

The module opens views to the best orientations in order to get free energy from the sun. The roof is designed with slope in order to obtain two benefits: allowing a second level for hosting the place for sleeping and for supporting PV panels over the roof.

The materials that are intended to be used were selected according to the criteria of efficiency and low cost. OSB panels for the inner skin, zinc panels as the outer skin and a structure based on wooden battens offers a fast construction process and at the same time allows a high quality control and appropriate solutions while seeking for a tight building closure.

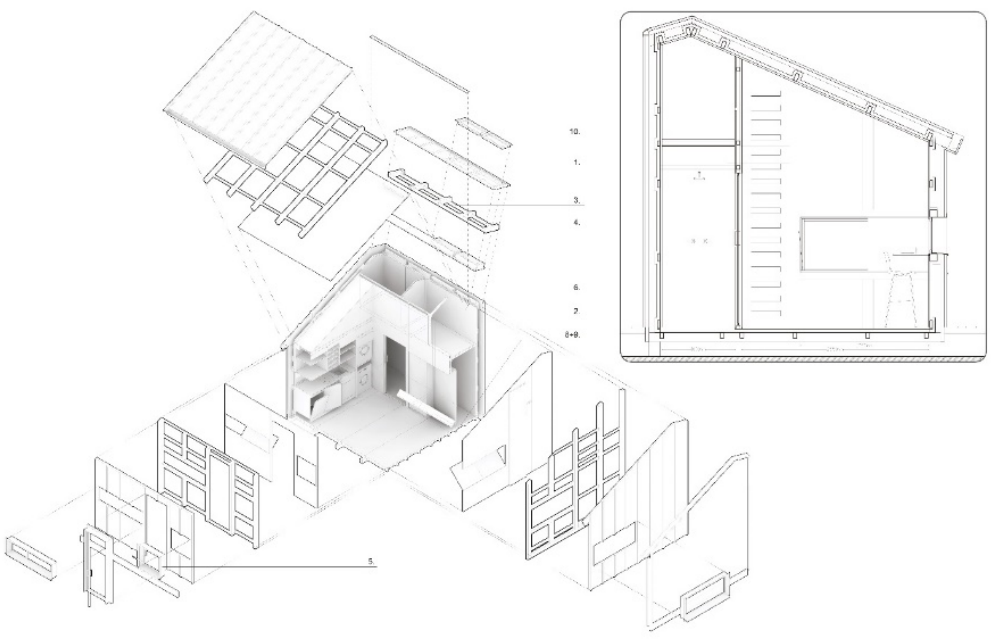

Figure 9: Axonometric view and section of the proposal module.

\subsection{The construction}

The construction on the roof of an existing building shows some technical limits. Other than urban regulations, something not considered in this study, are buildings with the same age as the ones that have been explored in this study, used to show some constructive damages due to the lack of quality and maintenance. The 


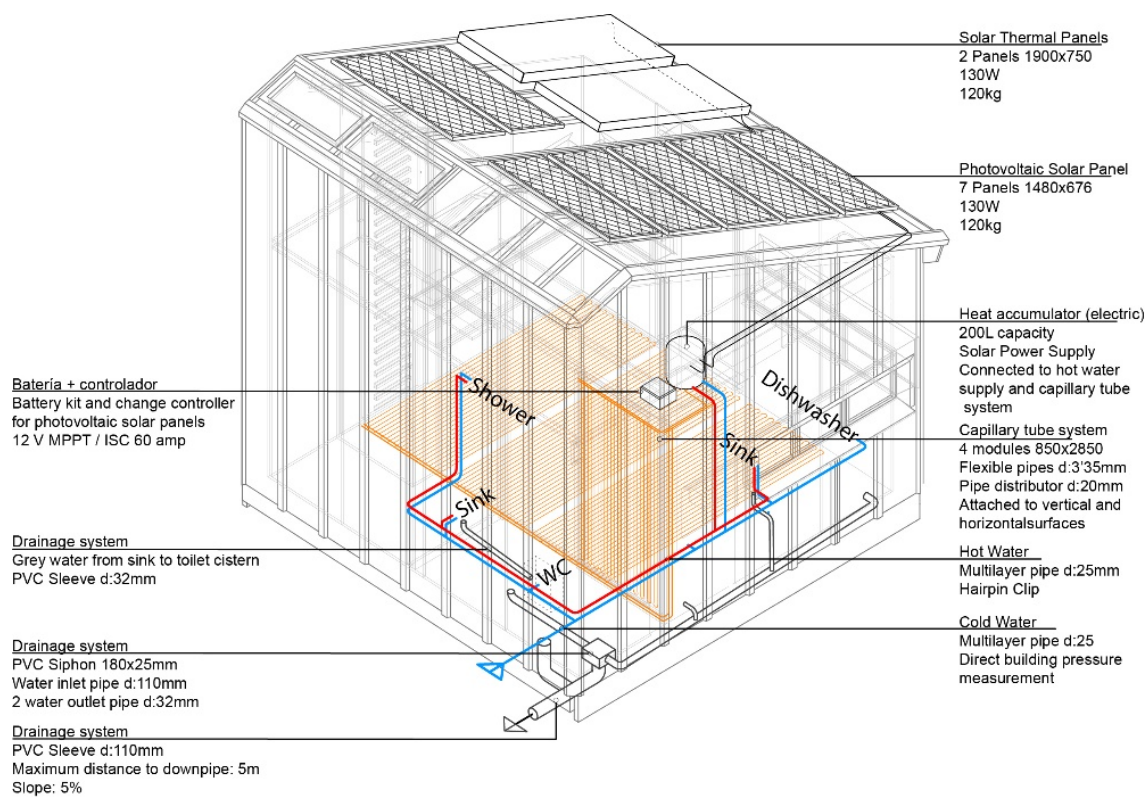

Figure 10: Axonometric facilities description.

module had to face this problem; so light construction is more than justified. With the above-mentioned materials, the weight of the module was $945 \mathrm{~kg}$ that corresponds to a load of $60 \mathrm{~kg} / \mathrm{m}^{2}$. This load was considered totally acceptable for almost any type of roof but for security reasons, in case slabs present structural deficiencies, it was designed a steel frame to be supported over the existing pillars or load bearing walls.

The self-sufficient design of the module must limit the impact over the existing building facilities. The use of solar and PV panels reduced the energy bill that related with a very low energy demand, limited the dependence over a most of the times obsolete electric installations. The module only needed to solve the connection with the existing water supply and with the building sewage system.

\subsection{Methodology}

As noted previously, the ultimate viability of this project would initially depend on the design of a construction that provides comfortable spaces with low energy demands. Once this had been achieved, a cost analysis was performed together with an analysis of the time taken to recover investment according to the potential value of a space such as this in the Paris rental market.

In order to assess the energy efficiency of the building and to design architecturally comfortable solutions, we modelled the module using BIM software. In this case, the initial design was executed using Autodesk Formit and 
its definition was subsequently completed using Autodesk Revit and more particularly using the Eco-Tect tool for assessing sustainable solutions.

An analysis of the behaviour of the energy demand of the module was carried out in order to assess the impact of each of the taken design and construction measures and evaluating the result. To calculate the different returns periods, we used the prices of the different services available in Paris when this research was conducted to compare these with the average rental prices in different parts of the city.

\section{Results}

\subsection{Cost assessment}

A cost analysis indicated that this intervention requires low investment owing to a high degree of industrialisation. Dry construction was achieved by using a wooden structure covered with metal panels equipped with sufficient thermal insulation to meet a reasonable energy demand for the climate in Paris.

In terms of interior environmental comfort, the module has under floor heating based on water pipes installed under the pavement. Energy for electricity and hot water is supplied by solar panels and photovoltaic panels, and can be boosted by conventional supply if necessary.

The internal cladding alternates wooden panels on vertical and horizontal surfaces in the living areas with ceramic cladding in wet areas. All indoor furniture is included as part of the fittings and therefore forms part of the design.

This yields a construction cost of 9,069.20 euros that corresponds to a ratio of $€ 566$ '83 per $\mathrm{m}^{2}$.

\subsection{Description of the scenarios}

In order to analyse the return of the investment it is necessary to compare the rental fee that this type of housing could obtain with a regular apartment in the casestudy area.

The total cost of the investment must gather all the expenses needed to fabricate the module, its transport and the process of placing it in the chosen building roof. It is also needed an evaluation of the energy performance of the module and its dependence over the regular electric supply in France. At this point, it was planned to develop three scenarios conditioned by the efficiency of the conditioning systems and the existence of PV panels in the roof of the module. Having PV panels in the roof could decrease the energy bill but at the same time fabrication costs raise. The three studied scenarios are identified in the following way:

Scenario 1: regular heat pump - no Solar/PV panels.

Scenario 2: high efficiency heat pump - no Solar/PV panels.

Scenario 3: high efficiency heat pump - With Solar/PV panels. 


\subsection{Return on investment scenarios}

An analysis of the costs obtained compared with the information published by the INSEE, selecting an average rental price of $€ 30 / \mathrm{m}^{2}$, offers the following return on investment scenarios [8]:

Table 1: Simulation scenarios.

\begin{tabular}{|c|c|c|c|}
\hline & Scenario 1 & Scenario 2 & Scenario 3 \\
\hline $\begin{array}{c}\text { Windows-wall ratio } \\
\text { Northern walls }\end{array}$ & $0 \%$ & $0 \%$ & $0 \%$ \\
\hline $\begin{array}{l}\text { Windows-wall ratio } \\
\text { Southern walls }\end{array}$ & $30 \%$ & $30 \%$ & $30 \%$ \\
\hline $\begin{array}{c}\text { Windows-wall ratio } \\
\text { Eastern }\end{array}$ & $30 \%$ & $30 \%$ & $30 \%$ \\
\hline $\begin{array}{c}\text { Window-wall ratio } \\
\text { Western walls }\end{array}$ & $30 \%$ & $30 \%$ & $30 \%$ \\
\hline Window glass & $\mathrm{Dbl} \mathrm{Clr}$ & $\mathrm{Dbl} \mathrm{Clr}$ & $\mathrm{Dbl} \mathrm{Clr}$ \\
\hline Wall construction & R13 Metal & R13 Metal & R13 Metal \\
\hline Roof construction & $\mathrm{R} 10$ & $\mathrm{R} 10$ & R10 \\
\hline Air infiltration & $1.2 \mathrm{ACH}$ & $1.2 \mathrm{ACH}$ & $1.2 \mathrm{ACH}$ \\
\hline Lighting efficiency & $7.53 \mathrm{~W} / \mathrm{m}^{2}$ & $7.53 \mathrm{~W} / \mathrm{m}^{2}$ & $7.53 \mathrm{~W} / \mathrm{m}^{2}$ \\
\hline $\begin{array}{c}\text { Conditioning } \\
\text { systems }\end{array}$ & $\begin{array}{c}\text { Average Heat } \\
\text { Pump }\end{array}$ & $\begin{array}{l}\text { High Eff. Heat } \\
\text { Pump }\end{array}$ & $\begin{array}{l}\text { High Eff. Heat } \\
\text { Pump }\end{array}$ \\
\hline Operating schedule & $12 / 7$ & $12 / 7$ & $12 / 7$ \\
\hline PV-panel efficiency & $20.4 \%$ & $20.4 \%$ & $20.4 \%$ \\
\hline PV-payback limit & 30 years & 30 years & 30 years \\
\hline PV surface coverage & $0 \%$ & $0 \%$ & $75 \%$ \\
\hline & $33,70 € \mathrm{~m}^{2} /$ yea & $30,60 € \mathrm{~m}^{2} /$ year & $12,70 € \mathrm{~m}^{2} / \mathrm{ye}$ \\
\hline
\end{tabular}

Table 2: $\quad$ Amortization scenarios.

\begin{tabular}{|c|c|c|c|}
\hline & Scenario 1 & Scenario 2 & Scenario 3 \\
\hline Execution cost & $7.301,00 €$ & $7.424,00 €$ & $9.069,00 €$ \\
\hline $\begin{array}{c}\text { Architects fees } \\
(10 \%)\end{array}$ & $730,10 €$ & $742,40 €$ & $906,90 €$ \\
\hline Permits (5\%) & $365,05 €$ & $371,20 €$ & $453,45 €$ \\
\hline Industrial benefit & $1.314,18 €$ & $1.336,32 €$ & $1.632,42 €$ \\
\hline Energy consumption & $539,20 € /$ year & $489,60 € /$ year & $203,20 € /$ year \\
\hline Total cost & $9.710,33 €$ & $9.873,92 €$ & $12.061,77 €$ \\
\hline Rent & $480,00 € /$ month & $480,00 € /$ month & $480,00 € /$ month \\
\hline Amortization & 21 months & 21 months & 25 months \\
\hline
\end{tabular}




\section{Conclusions}

Given that density has proven to be a desirable parameter in urban development, and that several strategies could be implemented simultaneously with a view to achieving greater density within urban spaces as a tool for city regeneration, the use of worthless space to expand or extend existing buildings has been shown to be viable.

Using rooftops as attractive areas in which efficient prefabricated systems can be installed to create new living spaces is economic, sustainable and repayable in the short to medium term. The different forms, sizes and types of unused space in major cities are easily adaptable, economically viable and present an impact/ cost ratio in building density that is difficult to surpass with any other constructionbased densification strategy.

The viability of these spaces stems from the transitory and intense nature of life in cities; given that a substantial segment of a city's population is transient, and that upon completing their education or training, these people will leave the city to be replaced by a new wave of people demanding the same types of space.

The use of these worthless spaces to host prefabricated modules can be an alternative to the existing rental market. In those buildings where its design permits this type of interventions, the modules can be a shelter option with a proper quality. It is also demonstrated that it has a reasonable return on investment and the energy bill limits its dependence over the regular facilities supplies.

\section{References}

[1] Maurer, R., Pitzer, M. \& Sebastian, S., Hedonic price indices for the Paris housing. Physica-Verlag, Heidelberg, pp. 11-12, 2004.

[2] De Palma, A., Motamedi, K., Picard, N., \& Waddell, P., Accessibility and environmental quality: inequality in the Paris housing market. European Transport, Trieste, pp. 52-53, 70-74, 2007.

[3] Perrel, C., Faits te chiffres - Ile-de-France. Faits et chiffres, Paris, pp. 1-3, 2013.

[4] Labrador, J., Couleaud, N. \& Trigano, L., Les conditions de logement en Ilede-France en 2013. Insee Analyses, Paris, pp. 1-4, 2015.

[5] OCDE, Better life index. http://www.oecdbetterlifeindex.org/es/countries /france-es/. [Last accessed: January 22nd, 2016].

[6] APUR - Atelier Parisien d'Urbanisme, Les chambres de service à Paris: $85 \%$ sont inhabitées, NOTE, Paris, pp. 1-4, 2015.

[7] Navarro Vera, J. R., \& Ortuño Padilla, A., Aproximación a la génesis de la contribución de la densidad en la noción de "ciudad compacta". EURE, Santiago de Chile, vol. 37, n 112, pp. 23-41, 2011.

[8] INSEE, Qualité des emplois. Fiches thématiques (INSEE), Paris, pp. 2-20, 2014. 